Thanks to all participants in our study who provided a breath of fresh air and a touch of humour. Thanks also to the members of the evaluating committee for taking the risk and having some fun together. Finally, thanks to Sarah Lafuente and Beatriz Serrano for help in the statistical analysis.

Contributors: All authors designed the study. MA and MJB designed the good looking score. AT and AML are guarantors. Funding: None

Competing interests: AT is a physician and AML is a surgeon. AT and MA have been happily married for 25 years. MA's good looking score for AT was not requested to avoid any problems at home for Christmas.
Ethical approval: Submitted to the institutional review board (IRB) but transferred for approval by the institutional beauty review (IBR), an ad hoc subcommittee of our institution.

1 Rowland PA, Coe NPW, Burchard KW, Pricolo VE. Factors affecting the professional image of physicians. Curr Surg 2005;62:214-6.

Isaacs D, Fitzgerald D. Seven alternatives to evidence based medicine. $B M J$ 1999;319:1618.

Gordon PM, Keohane SG, Herd RM. White coat effects. BMI 1995;311:1704.

4 Wikipedia. Snow White. http://en.wikipedia.org/wiki/Snow_White.

(Accepted 20 October 2006)

doi $10.1136 /$ bmj.39015.672373.80

\title{
Subcutaneous inflammation mimicking metastatic malignancy induced by injection of mistletoe extract
}

\author{
A I Finall, S A McIntosh, W D Thompson
}

We describe the histological features of subcutaneous inflammation induced by mistletoe, a popular Christmas decoration, when used as an anticancer complementary therapy. We also outline the use of extract of mistletoe in this context

\section{Case report}

A 61 year old woman attending a follow-up appointment two months after excision of tubular carcinoma of the breast complained of an abdominal wall mass. The lesion was subcutaneous, mildly tender, and had a nodular consistency. The patient was worried that the soft tissue mass might be a recurrence of follicular lymphoma, which had been diagnosed in April 2001, although her disease had been stable after five cycles of chemotherapy. The possibility of metastatic breast carcinoma was low considering the good prognostic features of tubular carcinoma.

The lesion was excised and the $4 \times 2 \times 2 \mathrm{~cm}$ mass of subcutaneous tissue seemed to consist solely of fibroadipose tissue. Microscopically, we identified a widespread infiltrate of plasma cells, lymphocytes, and eosinophils within the subcutaneous adipose tissue, in a septal and lobular distribution, indicating inflammation or panniculitisig.

A large proportion of the inflammatory cells were eosinophils. The lymphocytes formed follicular aggregates, particularly adjacent to blood vessels (fig 1). The architecture of these aggregates was benign. The lymphocytes were normal and immunohistochemistry confirmed a normal distribution of T cells and B cells. We found no evidence of light chain restriction, and Bcl-2 immunoreactivity was negative within the follicle centres, confirming the morphological impression of a reactive lymphoid infiltrate with no evidence of follicular lymphoma.

In addition to the perivascular lymphoid aggregates and panniculitis, lymphocytes and eosinophils were seen within small blood vessel walls, indicating vasculitis (fig 2). In summary, we found no evidence of malignancy after the tissue was examined microscopically on multiple levels.
Lobular panniculitis with paraseptal lymphoid follicles and vasculitis are found in lupus panniculitis, which is seen in systemic and discoid lupus erythematosus. ${ }^{1}$ Eosinophils have been reported in up to a quarter of patients with this disorder, making it a possible diagnosis in our patient. ${ }^{2}$ The microscopic features of the subcutaneous inflammation seen in dermatomyositis are indistinguishable from those seen in lupus, but a muscle biopsy would be needed to make such a diagnosis. ${ }^{3}$ Traumatic and factitial panniculitis are characterised by a mixed lobular and septal panniculitis, but they can be excluded in this case because of the absence of fat cyst formation, necrosis, and infiltrates of macrophages and multinucleate giant cells. ${ }^{4}$ Such features are also seen in post-steroid panniculitis, where multiple subcutaneous nodules develop up to a month after cessation of steroids. ${ }^{5}$

Our patient satisfied none of the 11 diagnostic criteria for systemic lupus erythematosus as set out by the American Rheumatism Association. ${ }^{6}$ After discussion with her surgeon, it transpired that the patient had been receiving subcutaneous injections of mistletoe extract as complementary therapy aimed at treating her lymphoma. She used an aqueous, whole plant extract of mistletoe grown on ash trees, called "Abnoba

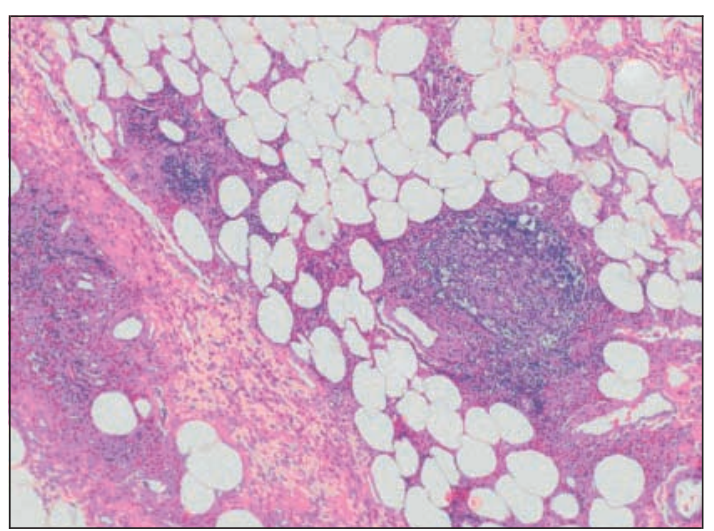

Fig 1 Medium power view ( $\times 200)$ of follicular aggregates of lymphoid cells in a perivascular distribution with a heavy infiltrate of eosinophils in the background
Department of Histopathology, University Hospital of Wales, Cardiff and Vale NHS Trust, Cardiff CF14 4XW A I Finall specialist registrar, histopathology

Unit of Breast Surgery, Aberdeen Royal Infirmary, Aberdeen AB25 2ZD

S A McIntosh consultant surgeon W D Thompson consultant histopathologist Correspondence to: A Finall Alison.Finall@ CardiffandVale.wales. nhs.uk

BMJ 2006;333:1293-4 




Fig 2 High power view $(\times 400)$ showing vasculitis-small blood vessel destruction and inflammation with a prominent eosinophilic component. Note the red blood cells within the vessel lumens

viscum fraxini." This was a self administered subcutaneous injection (20 mg three times a week), which she started 12 months before presentation. She had heard about the use of mistletoe extract in palliative oncology from a friend, and she was referred to a complementary therapist through her general practitioner. She is still in remission two and a half years later with no further side effects. Her injection site corresponded with the site of excision so, in view of her negative investigations, signs, and symptoms of lupus erythematosus, we considered the microscopic features to be a direct inflammatory response to mistletoe extract and conducted a review of the literature to compare our findings.

\section{Discussion}

Mistletoe (Viscum album) is a semiparasitic woody perennial that grows on several species of tree, including elm, apple, pine, and oak. ${ }^{78}$ It is used as a Christmas decoration in the United Kingdom with the tradition of kissing any person who lingers under it.

Mistletoe has been used to treat hypertension, headaches, menstrual symptoms, and arthritis. ${ }^{8}$ The first reference to its medical use is in the Bible as a cure for epilepsy. The young King David is said to have seen a woman collapse in a fit. An angel appeared to him as he prayed for a remedy, announcing "Whoever wears the oak mistletoe in a finger ring on the right hand, so that the mistletoe touches the hand, will never again be bothered by the falling sickness." Today, despite the lack of robust data supporting the use of mistletoe as an anticancer drug, it is widely used in middle Europe; around $€ 23 \mathrm{~m}(£ 16 \mathrm{~m} ; \$ 30 \mathrm{~m})$ is spent on the preparation each year, ${ }^{9}$ and up to two thirds of oncology patients use it. ${ }^{10}$ Sixteen randomised controlled trials have been published to date, many of which lack formal statistical power calculations and enlist small numbers of patients. ${ }^{710}{ }^{11}$ Several of these studies analysed quality of life variables as their major outcomes and failed to blind patients to their treatment, thereby severely biasing their results. ${ }^{10}{ }^{11}$ The evidence of benefit from human studies is weak, but animal studies and in vitro laboratory evidence suggest that mistletoe may be beneficial to cancer patients. ${ }^{7}$ Rigorous randomised controlled trials are needed to provide conclusive data in humans. ${ }^{71011}$
Local reactions have been documented previously, usually manifesting as erythema or pain. ${ }^{12}$ Two reports of histologically assessed inflammation induced by mistletoe exist in the medical literature. A 61 year old man with a T3NXMX pancreatic adenocarcinoma who was treated with once weekly intratumorous and peritumorous injections of mistletoe for five weeks underwent diagnostic needle core biopsy on day 28 after starting treatment. The biopsy showed adenocarcinoma admixed with neutrophils and eosinophils. ${ }^{13}$ A further study documents the histology of seven patients with subcutaneous inflammation induced by whole plant mistletoe extract. The microscopic pattern was of a dense perivascular lymphoid infiltrate and increased monocytes. ${ }^{14}$ An infiltrate of plasma cells or eosinophils was not seen. Both accounts support the notion that the microscopic features of panniculitis in our case are caused by subcutaneous mistletoe administration. Ours is the first documented account of a combined pattern of a heavy infiltrate of eosinophils, perivascular lymphoid aggregates, and mild vasculitis.

This case taught us the importance of good communication. We may never have known the underlying cause of the inflammation without an honest working relationship between the pathologists and surgeons, and between the surgeon and his patient. This story also shows that patients sometimes withhold information from us. In this case, the patient may have assumed that alternative therapies have no relevance in conventional medical consultations.

Many thanks to GT Williams, University Hospital of Wales, Cardiff, for help with the photographs.

AIF wrote the manuscript and helped manage the case as a trainee pathologist supervised by WDT. SAMcI helped in the clinical care of the patient and contributed her clinical history. WDT is guarantor.

Funding: None.

Competing interests: None declared.

Harris RB, Duncan SC, Ecker RI, Winkleman RK. Lymphoid follicles in subcutaneous inflammatory disease. Arch Dermatopathol 1999;21:365-8.

Peters MS, Su WPD. Eosinophils in lupus panniculitis and morphea profunda. J Cutan Pathol 1991;18:189-92.

Janis JF, Winkleman RK. Histopathology of the skin in dermatomyositis. Arch Dermatol 1968;97:640-50.

4 Winkleman RK, Barker SM. Factitial traumatic panniculitis. J Am Acad Dermatol 1985; 13:988-94.

5 Jaffe N, Hann HWL, Vawter GF. Post-steroid panniculitis in acute leukaemia. N Engl J Med 1971;284:366-7.
maffer

6 Hochberg MC. Updating the American College of Rheumatology revised criteria for the classification of systemic lupus erythematosus. Arthritis Rheum 1997;40:1725.

7 Kaegi E. Unconventional therapies for cancer: 3. Iscador. CMA 1998;158:1157-9.

8 National Cancer Institute. Mistletoe extracts. www.cancer.gov/ cancerinfo/pdq/cam/mistletoe.

9 Porter R. The greatest benefit to mankind. In: A medical history of humanity from antiquity to the present. London: Harper Collins, 1997:112.

10 Ernst E, Schmit K, Steuer-Vogt MK. Mistletoe for cancer? A systematic Ernst E, Schmit K, Steuer-Vogt MK. Mistletoe for cancer? A syste
review of randomised controlled trials. Int J Cancer 2003;107:262-7.

11 Kienle GS, Berrino F, Bussing A, Portalupi E, Rosenzweig S, Kiene H. Mistletoe in cancer-a systematic review on controlled clinical trials. EurJ Med Res 2003;8:109-19.

12 Mabed M, El-Helw L, Shamaa S. Phase II study of viscum fraxini-2 in patients with advanced hepatocellular carcinoma. $\mathrm{Br} J$ Cancer 2004;90:65-9.

13 Huber R, Barth H, Schmitt-Graf A, Klein R. Hypereosinophilia induced by high-dose intra-tumoral and peri-tumoral mistletoe application to a patient with pancreatic carcinoma. J Altern Complement Med 2000;16: 305-10.

14 Gorter RW, van Wiley M, Stoss M, Wollina U. Subcutaneous infiltrates induced by injection of mistletoe extracts (Iscador). Am J Health Ther 1998;5:181-7.

(Accepted 20 November 2006)

doi 10.1136/bmj.39044.460023.BE 